\title{
Effect of Temperature and Time of Stress Annealing on Magnetic Properties of Amorphous Microwires
}

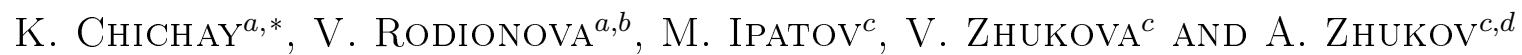 \\ ${ }^{a}$ Innovation Park and Institute of Physics and Technology, Immanuel Kant Baltic Federal University, \\ Kaliningrad, 236041, Russia \\ ${ }^{b}$ National University of Science and Technology "MISIS", Moscow, 119049, Russia \\ ${ }^{c}$ Dpto. Fisica de Materiales, Fac. Quimicas, UPV/EHU, San Sebastian, 20009, Spain \\ ${ }^{d}$ IKERBASQUE, Basque Foundation for Science, Bilbao, 48011, Spain
}

\begin{abstract}
In this work we studied influence of time and temperature of stress annealing on magnetic properties of amorphous Co-based and CoFeNi-based microwires. We showed that this type of treatment can be very effective for manipulation of magnetic properties of amorphous ferromagnetic glass-coated microwires. Co-based microwires keep S-shape hysteresis loop after any annealing. Annealing of Co-based microwires at different conditions allows tailoring of the saturation field. CoFeNi-based microwires present either S-shape or rectangular shape of the hysteresis loops depending on the value of the axial stress during the annealing. We demonstrated the possibility to change the switching field of microwires with acquired bistability in the range from 0.5 to $25 \mathrm{~A} / \mathrm{m}$.
\end{abstract}

DOI: 10.12693 /APhysPolA.127.600

PACS: 75.50.Bb, 75.50.Cc, 75.50.Kj, 75.60.Ej

\section{Introduction}

Amorphous ferromagnetic glass coated microwires are one of the perspective objects for creation on their basis of the coding system, giant magnetoimpedance (GMI) sensors and elements for magnetic memory application $[1,2]$. Difference of applications depends on microwires magnetic properties, i.e. on their micromagnetic structure [3, 4]. Micromagnetic structure of such microwires is defined by the distribution and value of the mechanical stresses inside the microwire and by the saturation magnetostriction coefficient $[1,3,4]$. Magnetic properties of microwire depend on sign of saturation magnetostriction coefficient: hysteresis loop is magnetically bistable for microwires with positive saturation magnetostriction constant and has S-shape for microwires with negative saturation magnetostriction constant of metallic nucleus.

For successful implementation of microwires in such devices it is very important to find the ways to control the magnetic properties of amorphous microwires. It can be realized by changing the microwires parameters (composition, diameter of metallic nucleus and thickness of glass shell) and by changing treatment conditions (temperature, annealing and etc.) [5-8].

In this work we showed the possibility to manipulate the magnetic properties of amorphous ferromagnetic microwires by annealing under applied stress and investigated influence of temperature and time of annealing.

* corresponding author; e-mail: ks.chichay@gmail.com

\section{Experimental details}

We investigated glass-coated microwires of three different compositions of metallic nucleus (one of them was produced from Co-based alloy and two of them - from CoNiFe-based alloys) prepared by the Taylor-Ulitovsky technique (also called in some publications as the drawing and quenching technique) described elsewhere [1-4] (see Table). Diameters of metallic nucleus and total diameters of glass-coated microwires also were different.

TABLE

The parameters of investigated microwires.

\begin{tabular}{l|c|c}
\hline \hline $\begin{array}{c}\text { Composition } \\
\text { of the metallic nucleus }\end{array}$ & $d[\mu \mathrm{m}]$ & $D[\mu \mathrm{m}]$ \\
\hline $\mathrm{Co}_{68.6} \mathrm{~B}_{14.8} \mathrm{Si}_{10} \mathrm{Mn}_{6.6}$ & 16.2 & 21.2 \\
$\mathrm{Co}_{68.7} \mathrm{Fe}_{4} \mathrm{Ni}_{1} \mathrm{~B}_{13} \mathrm{Si}_{11} \mathrm{Mo}_{2.3}$ & 17.0 & 23.6 \\
$\mathrm{Fe}_{3.85} \mathrm{Co}_{67.05} \mathrm{Ni}_{1.44} \mathrm{~B}_{11.53} \mathrm{Si}_{14.47} \mathrm{Mo}_{1.66}$ & 22.2 & 24.2 \\
$d$ - diameter of the metallic nucleus; \\
$D$ - total diameter of microwire in glass shell
\end{tabular}

Hysteresis loop of as-prepared and annealed microwires were measured by the induction method [9]. The microwires were annealed under applied tensile stresses and without applying of any stress at temperatures of 300 , 350 and $400^{\circ} \mathrm{C}$ for 5 and $60 \mathrm{~min}$. Range of applied tensile stresses varied from 100 to $300 \mathrm{MPa}$. After annealing the magnetic properties of microwires were studied again.

All samples (as-prepared and annealed microwires) have amorphous structure of metallic core $[6,10]$.

\section{Results and discussion}

Before annealing all samples had S-shape hysteresis loop (Fig. 1) typical for negative magnetostriction compositions. As we observed, annealing leads to significant changing of the magnetic properties. 


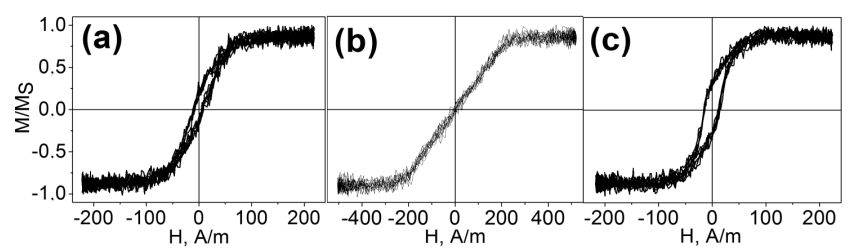

Fig. 1. Hysteresis loops of as-prepared microwires. Composition:

(a) $\mathrm{Co}_{68.6} \mathrm{~B}_{14.8} \mathrm{Si}_{10} \mathrm{Mn}_{6.6}$, (b) $\mathrm{Co}_{68.7} \mathrm{Fe}_{4} \mathrm{Ni}_{1} \mathrm{~B}_{13} \mathrm{Si}_{11} \mathrm{Mo}_{2.3}$,

(c) $\mathrm{Fe}_{3.85} \mathrm{Co}_{67.05} \mathrm{Ni}_{1.44} \mathrm{~B}_{11.53} \mathrm{Si}_{14.47} \mathrm{Mo}_{1.66}$.

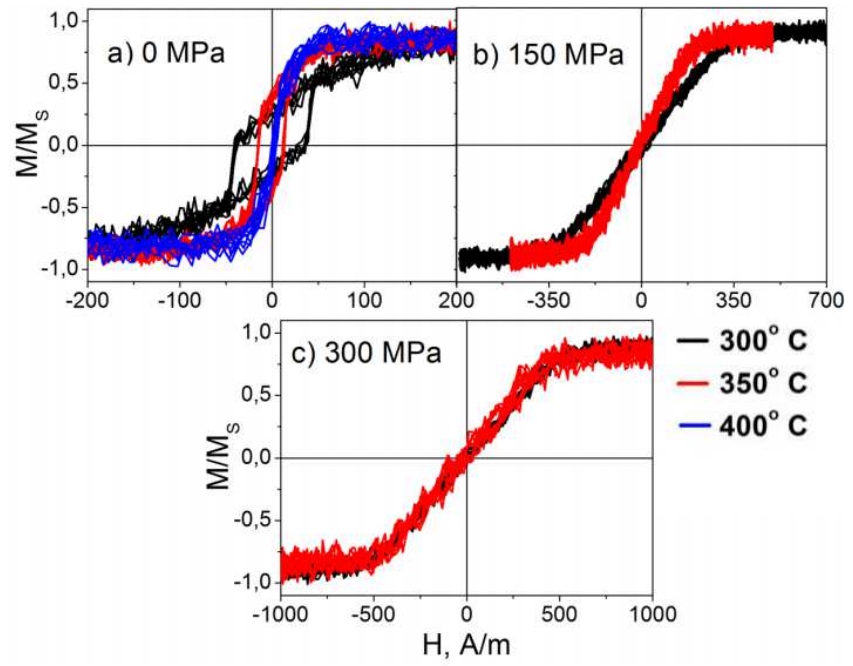

Fig. 2. Hysteresis loops for $\mathrm{Co}_{68.6} \mathrm{~B}_{14.8} \mathrm{Si}_{10} \mathrm{Mn}_{6.6} \mathrm{mi}-$ crowires, annealed at temperatures of $300^{\circ}, 350^{\circ}$ and $400{ }^{\circ} \mathrm{C}$ for 60 minutes (a) without any stress, (b) under stress of $150 \mathrm{MPa},(\mathrm{c})$ under stress of $300 \mathrm{MPa}$.

Co-based microwires were annealed for $60 \mathrm{~min}$ at temperatures, $T_{\mathrm{ann}}$, of 300,350 and $400^{\circ} \mathrm{C}$ under applied stresses up to $300 \mathrm{MPa}$ and without any stresses. Hysteresis loops of annealed samples are shown in Fig. 2. In the case of conventional annealing (without any stresses) we observed considerable increase of coercivity at $T_{\text {ann }}=300{ }^{\circ} \mathrm{C}$ (Fig. 2a). Coercive field is $40 \mathrm{~A} / \mathrm{m}$. Further increase of annealing temperature gave rise to decrease of coercivity and observation of nonhysteretic behaviour at $T_{\mathrm{ann}}=400^{\circ} \mathrm{C}$. Besides, saturation field of annealed microwires decreases from $190 \mathrm{~A} / \mathrm{m}$ to $60 \mathrm{~A} / \mathrm{m}$ with increase of $T_{\text {ann }}$ from 300 to $400{ }^{\circ} \mathrm{C}$. After stress annealing (applied stress of $150 \mathrm{MPa}$ ) we observed increase of saturation field as-compared with as-prepared microwires: from $100 \mathrm{~A} / \mathrm{m}$ - for as-prepared microwire up to $420 \mathrm{~A} / \mathrm{m}$ and $250 \mathrm{~A} / \mathrm{m}$ - for samples annealed at $300{ }^{\circ} \mathrm{C}$ and $350^{\circ} \mathrm{C}$, respectively. Increase of the annealing temperature leads to decrease of saturation field - the same situation as for annealing without applied stresses. Applying larger stresses - $300 \mathrm{MPa}$ - leads to further increase of saturation field $(510 \mathrm{~A} / \mathrm{m})$, but in this case changing of the temperature does not affect the magnetic properties.

Annealing of $\mathrm{Co}_{68.7} \mathrm{Fe}_{4} \mathrm{Ni}_{1} \mathrm{~B}_{13} \mathrm{Si}_{11} \mathrm{Mo}_{2.3}$ microwires leads to drastic changes of magnetic properties: all hys- teresis loops of annealed microwires present magnetically bistable character (see Fig. 3). Hysteresis loops of the samples annealed at temperatures of $300^{\circ} \mathrm{C}$ and $350{ }^{\circ} \mathrm{C}$ for 5 min without any stress and under applied stresses of 125 and $250 \mathrm{MPa}$ are presented in Fig. 3. We can see that increase of the annealing temperature results in increase of the switching field, $H_{\mathrm{s}}$, of microwires annealed without any stress: switching field of the sample annealed at $300^{\circ} \mathrm{C}$ is 3 times lower than for the sample annealed at $350^{\circ} \mathrm{C}$ (Fig. 3a). Stress annealed samples present different behavior. After stress annealing under lower applied stress (150 MPa) we observed slight decrease of the switching field with increase of the annealing temperature (Fig. 3b). With increase of the applied stress (at the same $T_{\text {ann }}$ ) decrease of the $\mathrm{H}_{\mathrm{s}}$ is more appreciated: switching field of sample annealed at $300^{\circ} \mathrm{C}$ is 3 times larger than switching field of sample annealed at $350{ }^{\circ} \mathrm{C}$ (Fig. 3c). Therefore, enhancement of applied stresses contributes to decrease of the switching field with increase of annealing temperature.

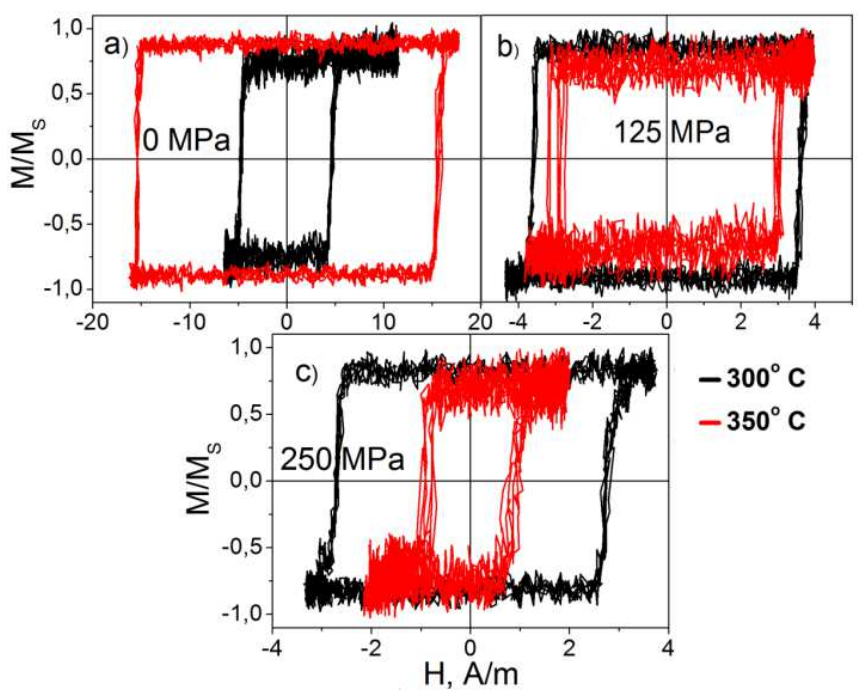

Fig. 3. Hysteresis loops for $\mathrm{Co}_{68.7} \mathrm{Fe}_{4} \mathrm{Ni}_{1} \mathrm{~B}_{13} \mathrm{Si}_{11} \mathrm{Mo}_{2.3}$ microwires annealed at $300^{\circ}$ and $350{ }^{\circ} \mathrm{C}$ for 5 minutes (a) without any stress, (b) under stress of $125 \mathrm{MPa}$ and (c) under stress of $250 \mathrm{MPa}$.

We can observe also significant differences of the hysteresis loops for the stress annealed microwires and annealed without any stress with increase of the annealing time (Fig. 4). Switching field of the microwire annealed for $60 \mathrm{~min}$ is considerable larger as-compared with the microwire annealed for 5 min (by 5 times), but applying of stress of $250 \mathrm{MPa}$ leads to sharp decrease of switching field for microwires annealed for $60 \mathrm{~min}$ - it is 2 times lower than the switching field of the sample annealed for $5 \mathrm{~min}$.

Hysteresis of $\mathrm{Fe}_{3.85} \mathrm{Co}_{67.05} \mathrm{Ni}_{1.44} \mathrm{~B}_{11.53} \mathrm{Si}_{14.47} \mathrm{Mo}_{1.66}$ microwires are also strongly affected by the annealing conditions (see Fig. 5). Those microwires annealed without stresses became magnetically bistable (Fig. 5a) and hysteresis loops of microwires annealed at 300 and $350{ }^{\circ} \mathrm{C}$ 


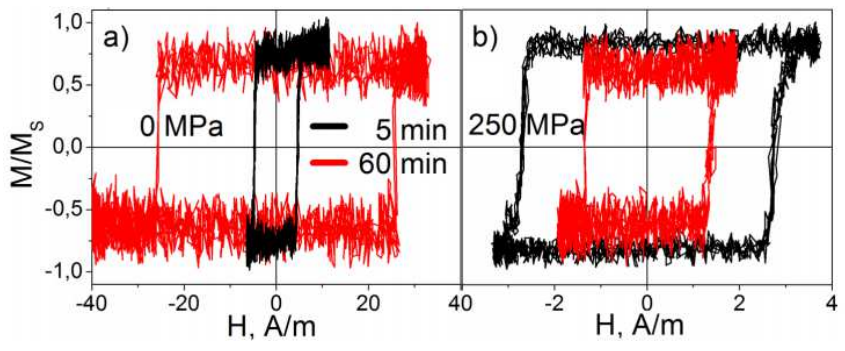

Fig. 4. Hysteresis loops for $\mathrm{Co}_{68}{ }_{7} \mathrm{Fe}_{4} \mathrm{Ni}_{1} \mathrm{~B}_{13} \mathrm{Si}_{11} \mathrm{Mo}_{2.3}$ microwires, annealed at temperature of $300{ }^{\circ} \mathrm{C}$ for 5 and 60 minutes (a) without any stress, (b) under stress of $250 \mathrm{MPa}$.

look very similar. But we can appreciate sharp change of magnetic properties after annealing at $T_{\text {ann }}=400^{\circ} \mathrm{C}$ : switching field decreases by 10 times from 5 to $0.5 \mathrm{~A} / \mathrm{m}$. Therefore we observed very small value of switching field for $\mathrm{FeCoNi}$-based microwire after conventional annealing at $400{ }^{\circ} \mathrm{C}$.

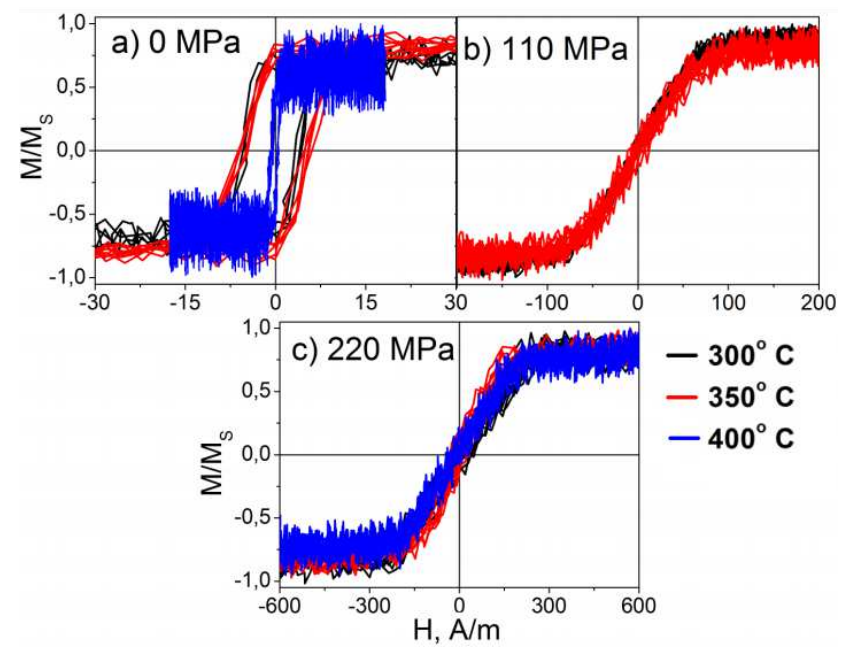

Fig. 5. Hysteresis loops for $\mathrm{Fe}_{3.85} \mathrm{Co}_{67.05} \mathrm{Ni}_{1.44} \mathrm{~B}_{11.53}$ $\mathrm{Si}_{14.47} \mathrm{Mo}_{1.66}$ microwires, annealed at temperatures of $300^{\circ}, 350^{\circ}$ and $400^{\circ} \mathrm{C}$ for 60 minutes (a) without any stress, (b) under stress of $150 \mathrm{MPa}$, (c) under stress of $300 \mathrm{MPa}$.

Stress annealed $\mathrm{Fe}_{3.85} \mathrm{Co}_{67.05} \mathrm{Ni}_{1.44} \mathrm{~B}_{11.53} \mathrm{Si}_{14.47} \mathrm{Mo}_{1.66}$ microwires keep S-shape, but they became nonhysteretic. Saturation field slightly increases after annealing under applying of $110 \mathrm{MPa}$ (it became $110 \mathrm{~A} / \mathrm{m}$ instead $100 \mathrm{~A} / \mathrm{m})$. But increase of applied tensile stress up to $220 \mathrm{MPa}$ leads to enhancement of saturation field by 2.5 times (about $250 \mathrm{~A} / \mathrm{m}$ ).

Annealing temperature does not significantly affect the hysteresis loops for $T_{\text {ann }}$ of 300,350 and $400^{\circ} \mathrm{C}$.

Drastic changes of the hysteresis loops from S-shape to bistable observed for FeCoNi-based alloys could be attributed to the change of the magnetostriction coefficient sign from negative to positive and corresponding change of the micromagnetic structure after annealing as recently observed in other similar Co-rich microwires [10].

\section{Conclusions}

We investigated the possibility to control the magnetic properties of amorphous ferromagnetic microwires by the stress annealing. We demonstrated that annealing conditions drastically affect the magnetic properties. We observed that Co-based microwires keep S-shaped hysteresis loop after annealing under applied stresses and without any stresses. Magnetic anisotropy fields of Co-based microwires are varied from 60 to $510 \mathrm{~A} / \mathrm{m}$. Depending on annealing conditions either rectangular or S-shaped hysteresis loop can be obtained in $\mathrm{CoNiFe-based} \mathrm{microwires.}$ Microwires with acquired bistability showed very wide range of switching field - from 0.5 to $25 \mathrm{~A} / \mathrm{m}$. We also found that change of the annealing time results in change of switching field up to 5 times for microwires with acquired bistability.

\section{Acknowledgments}

This work was supported by the Ministry of Education and Science of the Russian Federation in the framework of Increase Competitiveness Program of NUST "MISiS" and in the framework of government assignment (No. 3.2582.2014/K), by Spanish MINECO under Project MAT2013-47231-C2-1-P by the Basque Government under Saiotek13 PROMAGMI (S-PE13UN014) and DURADMAG (S-PE13UN007) projects, by RFBR, research projects No. 14-02-31850 and No. 14-32-50926.

\section{References}

[1] A. Zhukov, J. González, M. Vázquez, V. Larin, A. Torcunov, Encyclopedia of Nanoscience and Nanotechnology, Vol. 6, American Scientific Publishers, Baltimore 2004, p. 365.

[2] M. Vazquez, Handbook of Magnetism and Advanced Magnetic Materials, Vol. 4, Novel Materials, Wiley, Hoboken 2007, p. 2192.

[3] M. Vazquez, H. Chiriac, A. Zhukov, L. Panina, T. Uchiyama, Phys. Status Solidi A 208, 493 (2011).

[4] A. Zhukov, V. Zhukova, Magnetic sensors based on thin magnetically soft wires with tuneable magnet$i c \hat{A}$ properties and its applications, International Frequency Sensor Association IFSA Publ., Barcelona 2013, p. 164.

[5] V. Zhukova, J.M. Blanco, V. Rodionova, M. Ipatov, A. Zhukov, J. Appl. Phys. 111, 07E311 (2012).

[6] K. Chichay, V. Zhukova, V. Rodionova, M. Ipatov, A. Talaat, J.M. Blanco, J. Gonzalez, A. Zhukov, J. Appl. Phys. 113, 17A318 (2013).

[7] R. Varga, A. Zhukov, N. Usov, J.M. Blanco, J. Gonzalez, V. Zhukova, P. Vojtanik, J. Magn. Magn. Mater. 316, 337 (2007).

[8] V. Rodionova, V. Zhukova, M. Ilyn, M. Ipatov, N. Perov, A. Zhukov, Physica B 407, 1446 (2012).

[9] P. Aragoneses, J.M. Blanco, L. Dominguez, J. González, A. Zhukov, M. Vázquez, J. Phys. D Appl. Phys. 31, 3040 (1998).

[10] V. Zhukova, A. Talaat, M. Ipatov, J.M. Blanco, M.H. Phan, A.P. Zhukov, IEEE Trans. Magn. 50, 2005004 (2014). 